\title{
Research on Business Models Innovation Path for Electrical Power Substitution under "Three Types and Two Networks"
}

\author{
Wei Wang ${ }^{1,2}$ \\ ${ }^{1}$ School of Humanities and Social Sciences \\ North China Electric Power University \\ ${ }^{2}$ Beijing Energy Development Research Base \\ Beijing, China \\ wwfancy@163.com
}

\author{
Xin-he Zhang \\ China Electric Power Research Institute \\ State Grid Corporation of China \\ Beijing, China \\ zhangxinhe10@126.com
}

\author{
Gang Sun \\ Zhejiang Electric Power Research Institute \\ State Grid Corporation of China \\ Hangzhou, China \\ 672643764qq.com
}

\begin{abstract}
The popularization and application of electrical power substitution have produced great economic and social benefits. Whereas in the realistic development process, innovative business models are also required in order to promote the deep development of electrical power substitution. In 2019, the strategy of "three types and two networks" is proposed by the State Grid Corporation of China, which could provide the technology, platform and value base for the business models innovation of electrical power substitution. In the construction process of "three types and two networks" strategic system, Through SWOT analysis of the business model, we can further accelerate the sustainable development of electrical power substitution through innovating the existed business models.
\end{abstract}

Keywords-“Three Types and Two Networks"; Electrical Energy Substitution; Business Models; Energy Structure

\section{INTRODUCTION}

Optimizing the energy structure and achieving clean and low-carbon development is the essential requirement for promoting China's energy revolution and is an urgent need for China's economic and social transformation and development. As high-quality terminal energy, electric energy can improve energy efficiency and optimize energy structure. Electric energy substitution refers to the consumption of terminal energy, which uses electric energy instead of traditional fossil energy such as scattered burning of coal and oil. Through large-scale centralized transformation, fuel efficiency and pollutant emission can be improved, thereby improving the terminal energy structure and promoting environmental protection effect. Replacing coal, petroleum and other chemical fuels with clean electric energy is an inevitable way to optimize energy structure.

Supported by State grid corporation of China headquarters science and technology project "research on key technologies and system research and application of electric energy replacement effect improvement based on electric energy service management platform" (contract No. YD71-18-011)
With the continuous deepening of the new round of power system reform, the green energy strategy represented by electric energy replacement and clean substitution has been highlighted. Studies show that energy consumption accounts for $1 \%$ of the total energy consumption of the terminal, and energy consumption per unit of GDP can be reduced by about $4 \%$ [1]. Under the dual pressure of environmental protection and energy revolution, the global electricity and energy market is facing a major transformation. The development and utilization of clean energy and the substitution of electric energy for traditional primary energy have gradually become the mainstream direction and the state's policy support for the development of electrical energy substitution also mentioned the key strategic position. incorporating the applicable criteria that follow.

\section{THE ACHIEVEMENTS OF ELECTRIC ENERGY}

\section{SubSTITUTION AND ITS DeEP ObSTAClES to DEVELOPMENT}

On May 25, 2016, the "Guiding Opinions on Promoting Electrical Energy Substitution" (Development and Reform Energy[2016]No.1054), which was formulated by the National Development and Reform Commission and other departments, was officially issued, requiring electricity to be replaced by renewable energy, and some ultra-low emission coal-fired power units, which will contribute significantly to increasing the proportion of clean energy consumption and reducing the emission of air pollutants. The popularization and application of electric energy substitution have produced good economic and social benefits, According to $\mathrm{CEC}$ (China Electricity Council) data display, by the end of 2018, China had implemented a total of 110,000 electric energy substitution projects, and the cumulative replacement of electricity was 155.765 billion $\mathrm{kwh}$, an increase of $21.12 \%$ over the same period of last year, equivalent to reducing 60 million tons of 
loose coal in the energy consumption terminal. The state grid has completed 96,225 projects, and completed 115 billion kilowatt-hours of alternate power, with an annual growth of nearly 70\% from 2013 to 2018. China southern power grid corporation completed 5,582 projects and completed 13.6 billion kilowatt-hours of alternative electricity, effectively reducing the abandonment of wind, light and water and promoting the consumption of clean energy. The cumulative completion of electric energy substitution in China is equivalent to reducing the carbon dioxide, hydroxide and dust emissions by 5.827 million tons. The replacement of electric energy has achieved great success in recent years and will maintain a strong growth trend in the future. However, there are still obstacles to this deep development in the development of electric energy replacement, mainly in the following three aspects.

\section{A. The technical standards and laws and regulations of electric energy substitution lag behind}

Technical development is the strategic core of promoting electric energy substitution development. At present, there are many manufacturers with electric energy replacement technology, but their product quality lacks uniform technical standards, and product specifications, models and performance parameters are different. For example, in the field of electric vehicles, national standards have been established for conducting the charging system of electric vehicles in 2015. However, the products of different manufacturers have great differences in charging time and power conversion efficiency. So it is necessary to strengthen standard-setting from the legal and regulatory levels to encourage technological breakthroughs.

\section{B. The development of electric power substitution lacks innovative business models}

The business model of electric energy substitution mainly refers to the commercial investment and operation mode in the alternative development of electric energy. China's electric energy substitution projects are mainly concentrated in residents' decentralized "coal to electricity", cold storage, heat storage, electric vehicles, rail transit and other aspects, carried out in the form of contract energy management, equipment leasing, and leasing agent construction.

At present, the promotion of electric power replacement mainly relies on the government and state-owned enterprises such as the state grid, and the participation of social capital and enterprises is relatively low, a relatively complete industrial chain has not been formed. At the same time, due to the outdated business model, there are problems such as funding gap and lack of professional personnel in the process of project development[2].

\section{The lack of obvious economic benefits leads to the lack of positive substitution willingness of users}

In the field of replacing clean heating coal with electricity in northern China, the transformation of users requires various inputs, including the cost of coal-to-electricity transformation and investment in heating equipment. Although rural residents' psychological expectations of the living environment, heating methods and related consumption have gradually increased, their ability to withstand heating costs is still limited. At the present stage, the government has adopted the subsidy mode of "use first, supplement later". Users are afraid to use it freely for fear of insufficient subsidies and high operating costs. This phenomenon is still common in the heating season.

\section{The "Three Types AND TwO NeTWORKS" STRATEGIC SySTEM PROVIDES A REALISTIC BASIS FOR BUSINESS MODEL INNOVATION}

In 2019, the state grid proposed to focus on building a world-class energy Internet enterprise, keeping its innovation and responsibility, creating a "hub-type, platform-type, and shared-type" enterprise, and building and operating a "strong smart grid, ubiquitous power Internet of Things", which is the development strategy of "three types and two networks". "Type three and type two net" is an organic whole, "type three" is the means, "type three" is the goal, and the two are the relationship between means and goal. The state grid corporation of China aims to transform itself into a "type three" enterprise by constructing and operating "two networks" well.

\section{A. "Hub-Type " provides the technical basis for the innovation of electric energy substitution business model}

In terms of the specific connotation of "three types and two networks", "hub type" reflects the industrial attributes of the state grid corporation. The core embodiment of "hub type" is the "strong smart grid" based on UHV(ultra-high voltage), which can effectively support the supply-side structural reform. The construction of "three-type and two-network" is conducive to supporting the effective grid connection of intermittent distributed power supply through the intelligent distribution network, solving the problem of coordinated utilization of distributed power supply, and promoting the long-distance transportation through the construction of UHV power grid to realize the replacement of clean electric energy. UHV transmission network in China has the characteristics of longdistance, large capacity and low loss, which is the main way for West to East. At present, the development pattern of UHV is based on the "three horizontals, three verticals and one ring network" as the UHV backbone network, forming a resource allocation pattern for the transmission of electricity from the west to the south. During the "13th Five-Year Plan" period, UHV construction will be further accelerated and gradually inclined to the northwest. China will focus on optimizing two UHV synchronous power grids in the west (northwest China + Sichuan, Chongqing and Tibet) and the east ("Sanhua "and three northeast provinces and Inner Mongolia), forming a" five horizontal and five vertical "pattern of 29 UHV lines with clear structure of sending and receiving ends.

\section{B. "Platform -Type " provides platform support for the innovation of electric energy substitution business model}

"Platform type " reflects the network attributes of the state grid. The substitution of electric energy necessarily requires the network to transmit electric energy which inevitably requires an intelligent platform. The core of energy Internet lies in the multi-objective optimization of cost, price and 
efficiency under the balance constraint of energy supply-side and demand-side, Through the technology platform, it can fully sense the whole process of energy and function, so as to conduct efficient matching based on platform,achieving the goal of efficient, clean and economical utilization of energy

The future of energy Internet must be based on "strong smart grid" and " ubiquitous power Internet of Things " as the foundation, the ubiquitous Internet of Things can power users and their equipment, power grid enterprises and their equipment, power generation enterprises and their equipment, suppliers and its equipment, as well as people and things, are connected to generate shared data, serving users, power grids, power generation, suppliers and social services, thus concentrating resources on the grid, promoting supply and demand docking, reorganization of elements, and innovation, creating comprehensive energy allocation innovation platform, service platform and new business, new forms and new mode of development platform.

\section{C. "Shared-type " provides a valuable basis for the innovation of electric energy substitution business model}

"Shared type " reflects the social attributes of the state grid corporation. Through the construction and operation of a strong smart grid and ubiquitous power Internet of Things, support the grid company to interact with users and other entities, technical exchanges and business cooperation, jointly create a co-construction and win-win energy Internet ecosystem, to achieve the data sharing, results sharing and value sharing between the state grid corporation and users and other entities. This platform should first share clean new energy with the people, and carry out the large-scale and longdistance stable transmission of clean electricity through UHV backbone grid to solve the problem of wind, light and water clean energy consumption in the northwest, northeast and North China and southwest regions.

In brief, the essence of "the three types and two networks" strategic is based on the Internet thinking, playing the hub role of the state grid corporation, promoting the strong smart grid and the ubiquitous power Internet of Things to collaborate to form an energy Internet platform, driving the upstream and downstream of the industry chain and the whole society to share development achievements and fully embodying new ideas and new ideas of openness, cooperation and mutual benefit will effectively promote clean energy and its alternative development.

\section{THE INNOVATIVE PATH OF ELECTRIC ENERGY TO SUBSTITUTION BUSINESS MODEL UNDER "THREE TYPES AND TWO NETWORKS"}

In the development of electric energy substitution, it is necessary to strengthen the technological innovation, management innovation and business innovation with the supply-side structural reform as the mainline. The connotation of the "supply-side" structural reform is driven by innovation, which inevitably needs to strengthen the business model innovation of electric energy substitution.
A. The construction of "three-type and two-network" further strengthens the platform foundation for the innovation of electric energy replacement business model

The development of "three types and two networks" will actually build a new energy ecosystem under the energy revolution, which will inevitably give birth to new business models and development opportunities. "Three-type and twonetwork" will build a standard system that is supported by the whole industry chain, with supporting equipment, data and services, integrates upstream and downstream industries through all-round cooperation with well-known enterprises, universities and scientific research institutions at home and abroad ,and reconstruct the internal and external ecology of the energy industry, stimulate the industry to grow in all directions, and create a new era of energy Internet industry ecosystem. Therefore, the substitution of electric energy under the "three types and two networks" can be based on comprehensive sensing and innovation platform operation, guiding the formation of intelligent electric energy substitution, reducing costs through various forms of transactions, and introducing new third-party platform operations to seek new ones. Value transfer, and finally through the use of energy intelligence and the Internet, to form a new strategy and new methods and new formats of electrical energy replacement.

The state grid can actively promote the development of electric energy substitution by constructing and innovating business models that are conducive to the development are conducive to the development of alternative energy. As shown in fig1, the "three types and two networks" strategic system has built a broad business model innovation platform for the development of electric energy substitution.

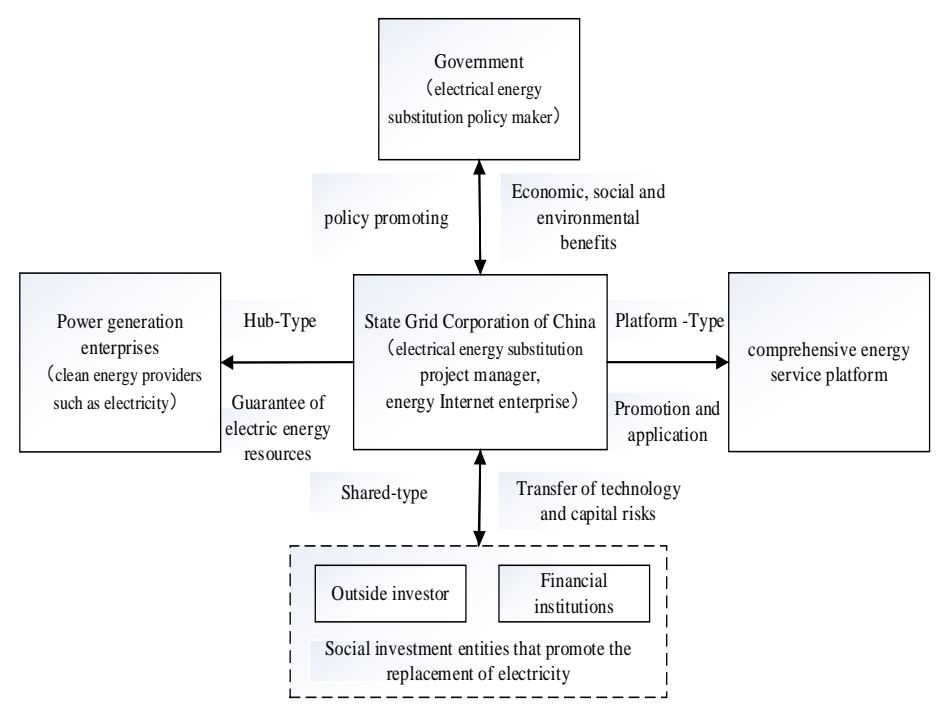

Fig.1. The basic support of "three types and two networks" strategic system for the development of electric energy substitution

\section{B. Promoting the development of electric energy substitution through the innovation of comprehensive energy service}

The development of the electric power replacement business model involves various aspects and multiple paths. At present, China's electric power substitution is still in the early 
construction areas require highly specialized technologies and

stage of development, and the business model has not formed a complete and available market-oriented model. With the support of the "three-type and two-network" strategic system, by the high quality grid services as the cornerstone and entrance, give play to the advantage of vast user resource to create a comprehensive intelligent service platform covering the government, terminal customers and the upstream and downstream of the industrial chain, which can provide information docking, the matching of supply and demand, dealmaking and other services, drainage for emerging business users[4].

By strengthening the building of innovative capabilities such as equipment monitoring, grid interaction, account management, and customer service, empowering grid companies and emerging business entities, can build a threelevel integrated smart energy service system of "company, area, and zone", which will certainly facilitate integration of the electric energy substitutes outside the national grid ,to share the win-win interests, comprehensive energy through innovation service mode, play their own core advantage in energy configuration platform and value, gathering all kinds of resources, promote the development of electric energy alternative.

\section{Promoting the development of electric energy substitution with PPP business model innovation}

In recent years, the introduction of social investment has become one of the important business models for the replacement of foreign electric energy. Public-Private Partnership ( the PPP mode) refers to the project cooperation between government and private institutions to provide public goods, services or build urban Public facilities. In the PPP mode, the government selects social capital through public bidding, and both parties are responsible for the design, financing, construction, operation, operation and maintenance of the project. In December 2015, the number of projects involving green low-carbon fields in the second batch of PPP projects increased to 370 [5], and the application of PPP mode in the field of electric energy substitution has achieved initial results.

The PPP mode in the field of electric energy substitution is feasible. First, China is still a developing country, and the market has not yet fully played its fundamental role and key role in resource allocation. The PPP model has exactly the characteristics of combining government supervision and market mechanism to adapt to the current situation of China's social and economic development. Second, the PPP model is mainly applicable to government public services and infrastructure projects [6]. Most of the electric energy replacement projects belong to the municipal infrastructure of energy, which has strong publicity, requires a large number of funds and limited short-term economic benefits. The PPP model can promote the private sector to share part of the public sector funds or areas with insufficient operational efficiency. Third, comprehensive energy services are taken seriously increasingly, leading to significant transformation of the electric power industry. Smart grids, distributed energy, and new energy vehicle charging piles are the supporting foundations for the replacement of electric energy or the key equipment, such as charging pile supported the foundation or key construction requires highly specialized in the field of technology, equipment and personnel. The PPP mode can effectively integrate their advantages resources by the government and the society, not only play the role of the government's policy provision and comprehensive coordination, but also help the company to play a professional advantage in the capital, technology, equipment and operation management and so on, thereby facilitating solve the problem of insufficient government professionalism in certain areas.

\section{CONCLUSION}

The substitution of electric energy requires the innovation of business model. The State Grid Corporation of China launched the "three-type and two-network" strategy, which contains the innovative appeal of business models and the business model platform and technical support for promoting the development of electric energy substitution, through comprehensive energy service models and the innovation of the business model of PPP mode can not only promote the development of electric energy substitution but also further promote the realization of the "three-type two-network" strategy.

\section{ACKNOWLEDGMENT}

The paper Supported by State grid corporation of China headquarters science and technology project "research on key technologies and system research and application of electric energy replacement effect improvement based on electric energy service management platform" (contract No.: YD71-18011).

\section{REFERENCES}

[1] Kehua Jia. Comprehensive replacement of electric energy, China Energy News. May 2016.

[2] Bingqing Guo, Yu Shen, The business model of electric energy replacement technology application, China Electric Power, pp.139-146, September 2018.

[3] Qunli, Zhang, Zhiming Wang, Yangyang Hao. Research on Problems and Reformation Promotion Models of Beijing Clean Energy Reconstruction. Refrigeration and Air Conditioning, vol.17(3) pp.90-94, 2017.

[4] Ming Zeng. "Three Types and Two Networks" Strategic Connotation and Implementation of China State Grid Corporation. China Power Enterprise Management, vol(2),2019.

[5] Xiaoming Ma, Hui Su. Development and Suggestions of the PPP Model under the Background of Green Finance in China. Modern Management Science, 2017.

[6] Xiao Song. The National Energy Administration will promote the PPP model in the energy field. China Coal, pp.142-142, 2016 